\title{
Absorption and distribution of phosphorus from Typha under arsenic
}

\author{
W. Ren, G.Y. Yang, W. Yan, L. Hou \& Y.G. Liu \\ Research Institute of Rural Sewage Treatment and College of Ecology and Soil \& Water Conservation, \\ Southwest Forestry University, Kunming, P.R. China
}

\begin{abstract}
In order to reveal absorption and distribution of phosphorus under from under arsenic. By the method of arsenic addition, the concentration gradient of arsenic in the sediment was set $0,50,100,150,200,400$ and $600 \mathrm{mg} \mathrm{kg}^{-1}$. To investigate the absorption and distribution of different parts of Typha at different arsenic concentrations. The results show: (1) With the increase of arsenic concentration in the sediments, Typha on phosphorus absorption was first increased and then decreased. The absorption of arsenic also increased first, then decreased and tended to be stable, and the absorption of phosphorus and arsenic reached the peak under $150 \mathrm{mg} \mathrm{kg}^{-1}$ stress. Add different concentrations of arsenic affected the absorption of phosphorus and arsenic in Typha, may be related to the biomass of plants. (2) The uptake of phosphorus in the aerial part of Cattail was significantly higher than that of the root, while the absorption and accumulation of arsenic were opposite.
\end{abstract}

\section{INTRODUCTION}

Arsenic and arsenic compounds are common environmental pollutants, endangering the ecological environment, and seriously threatening human health (Mandal \& Suzuki, 2002). Phosphorus is a necessary nutrient element for plant growth. It is also an important limiting element for eutrophication in lakes. In view of the high risk of eutrophication in the plateau lakes. However, the lake area is vast and the hydrological conditions are complex. It is difficult to realize the large-scale restore by physical and chemical methods. Phytoremediation is the ecological treatment method which is concerned at present. Wetland plants can remove pollutants in water by absorption, adsorption and enrichment ( $\mathrm{Tu} \& \mathrm{Ma}, 2003$ ). The less studies on the distribution and absorption of phosphorus and arsenic. Pot culture and gradient arsenic stress were used in this study. The absorption and distribution of phosphorus were studied under arsenic stress. The relationship between arsenic and phosphorus in wetland plants was analyzed in order to provide theoretical basis and technical support for phytoremediation of plateau lakes with eutrophication and heavy metal arsenic pollution.

\section{MATERIALS \& METHODS}

The cattail as the research object, through the pot culture and adding different concentrations of arsenic by way of indoor simulation experiment. Set the arsenic pollution in the sediment concentration: $0,50,100$, $150,200,400,600 \mathrm{mg} \mathrm{kg}^{-1}$, were roughly the same biomass and growth status of seedlings planted in good soil for pollution stress, and unified equal amount of garden fertilizer, according to evaporation of soil moisture, not to keep the water regularly. The soil is
Table 1. Basic properties of the tested soil.

\begin{tabular}{lc}
\hline Property & Value \\
\hline $\mathrm{pH}$ & 3.97 \\
$\mathrm{TP}\left(\mathrm{g} \mathrm{kg}^{-1}\right)$ & $0.57 \pm 0.004$ \\
$\mathrm{TAs}\left(\mathrm{mg} \mathrm{kg}^{-1}\right)$ & $8.39 \pm 0.64$ \\
$\mathrm{TCa}\left(\mathrm{g} \mathrm{kg}^{-1}\right)$ & $2.86 \pm 0.58$ \\
$\mathrm{OM}\left(\mathrm{g} \mathrm{kg}^{-1}\right)$ & $28.84 \pm 0.81$ \\
\hline
\end{tabular}

submerged. Plants were harvested after $45 \mathrm{~d}$ plants, and determination of plant height, root length, upper (lower) dry weight and the content of arsenic, explore typical wetland plants Typha in plants under different concentrations of arsenic uptake and distribution of various parts of the.

\section{RESULTS AND DISCUSSION}

\subsection{Basic properties of the tested soil}

Some of tested soil sediments were listed in Table 1.

\subsection{Effects of arsenic pollution on the growth of Typha habitat}

Different arsenic pollution habitat Typha growth showed increased before decreasing rule. The high content of arsenic in cattail plant $0 \sim 150 \mathrm{mg} \mathrm{kg}^{-1}$ soil increased volatility, and reached the peak at $150 \mathrm{mg} \mathrm{kg}^{-1}$ in the high pollution, arsenic pollution decreased significantly (Fig. 1). Arsenic pollution in the environment, underground cattail than shoot the degree of toxicity was significantly increased, root length reached maximum in the arsenic content of $50 \mathrm{mg} \mathrm{kg}^{-1}$, higher than $50 \mathrm{mg} \mathrm{kg}^{-1}$ showed a downward trend, and decreased significantly. 

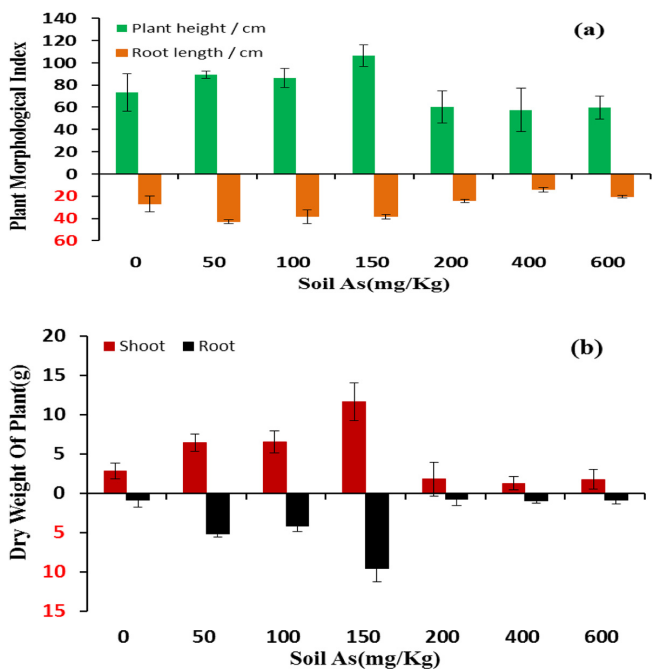

Figure 1. Effects of arsenic pollution on the growth of Typha habitat: a) Plant morphological index, b) Dry weight of plant.
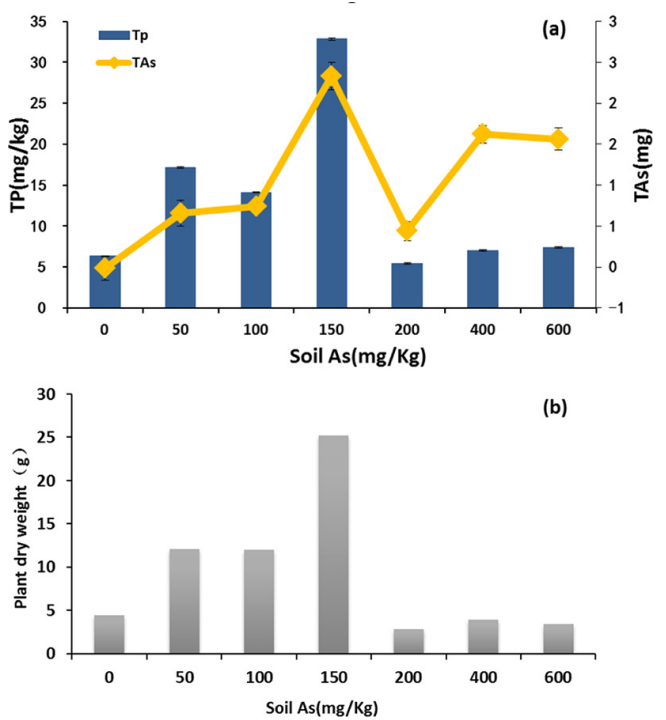

Figure 2. Effects of arsenic on the absorption of phosphorus and arsenic in cedar and its effect on the biomass of cattail: a) Absorption of phosphorus and arsenic from cattails, b) Dry weight of persimmon plants.

\subsection{Absorption of phosphorus and arsenic and its effect on the biomass of Typha angustifolia in arsenic contaminated habitats}

With the increase of arsenic concentration of exogenous pollutants, the absorption of phosphorus and arsenic increased first and then decreased, and the absorption of phosphorus arsenic reached the peak value in the soil with arsenic content of $150 \mathrm{mg} \mathrm{kg}^{-1}$ (Fig. 2) - synergistic effect. This is consistent with the law of dry weight change of the plant, indicating

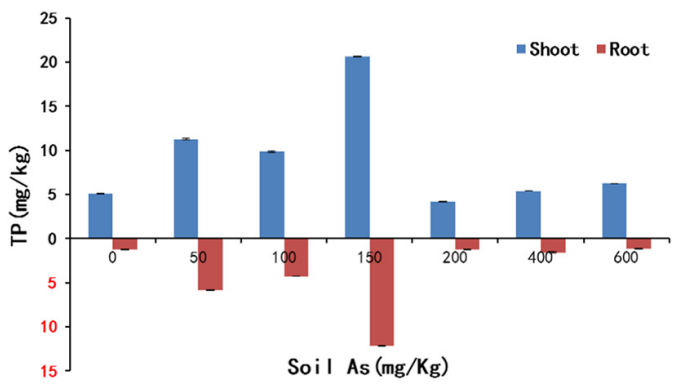

Figure 3. Distribution of phosphorus from Typha under arsenic.

that the addition of different concentrations of arsenic affects the absorption of phosphorus arsenic, which may be related to the biomass of the plant.

\subsection{Distribution of phosphorus from Typha under arsenic}

With the increase of arsenic concentration of exogenous pollutants, the uptake of phosphorus was higher than that of roots (Fig. 3). The transport coefficient of cedar is higher, indicating that cattail can absorb phosphorus quickly, which is less affected by the change of arsenic concentration. In the arsenic polluted habitat, the enrichment ability of phosphorus in the upper part and the underground part of cattail was weak.

\section{CONCLUSIONS}

1) With the increase of arsenic concentration in the sediments, on phosphorus and arsenic absorption was first increased and then decreased. Add different concentrations of arsenic affected the absorption of phosphorus and arsenic in Typha, may be related to the biomass of plants.

2) Typha on the part of the absorption of phosphorus accumulation was significantly higher than that of the root.

3) The phosphorus transport coefficient of different parts of Typha angustifolia was higher, while the arsenic was lower.

\section{ACKNOWLEDGEMENTS}

This project was supported by the National Natural Science Foundation of China (grants 31560147 and 51469030).

\section{REFERENCES}

Mandal, B.K \& Suzuki, K.T. 2002. Arsenic round the world: a review. Talanta 58(1): 201-235.

Tu, S. \& Ma, L.Q. 2003. Interactive effects of $\mathrm{pH}$, arsenic and phosphorus on uptake of As and $\mathrm{P}$ and growth of the arsenic hyper accumulator Pteris vittata L. under hydroponic conditions. Environ. Exper. Bot. 50(3): 243-251. 